\title{
Evidence-based medicine, user involvement and the post-modern paradigm
}

\author{
Richard Laugharne
}

Working in general psychiatry requires us to live with tensions. We have to live with the tension between the paternalism of compulsory admissions and advocating the autonomy and rights of people with a mental illness. A further tension is exacerbated by two movements of recent years, evidence-based medicine and user involvement. These are broadly to be welcomed, but will ultimately bring psychiatry further into the conflict between the 'modern' and 'post-modern' views of the world.

Most of us will be familiar with the following situation. We have seen and assessed a patient and have given advice as to the most appropriate management. The person listens attentively and then says he or she does not agree with the proposed treatment and feels an alternative therapy would be more suited to his or her needs. The psychiatrist explains that according to the available evidence, the suggested management is the most effective and the alternative, which might be very expensive in cost, does not usually work for the patient's problem. The patient replies that what works for the majority would not necessarily work for them, and that he or she feels confident about knowing what will be effective.

This scenario is probably as old as medicine. However, this tension is becoming more difficult to deal with in recent times. First, in the past it was more acceptable for patients to simply refuse treatment and seek their own solutions. Now if any risk is involved clinicians are being held responsible for 'assertively treating' patients. Second, there is a conflict between the modernist philosophy of medicine and post-modern spirit in society. This has been exacerbated by the increased prominence of outcome measures in clinical governance and evidence-based medicine, both highly modernist concepts.

\section{Modern versus post-modern}

Modernism is a product of the Enlightenment and as such, in human history, is relatively recent. Its main outlook on reality is rationalist, materialist and reductionist. This is the basis of scientific endeavour: that the material world follows logical rules that can be measured. From these measurements we can form rational assumptions that explain the world, test these assumptions and so apply these rules to effect change through technology. This philosophy actually took a long time to effect medicine, but has now made a huge impact (Leggett, 1997). Few would deny that modern medicine has hugely benefited the human race in many ways - and that modernism has brought the human race close to self-destruction through military technology and ecological disaster (if the worst predictions prove to be accurate).

Modernism as a philosophy began to look less than complete at the end of the last century and the twentieth century has hastened that revision. One reason is that it has denied the individuality of people, reducing them either to their component parts (as in the emphasis of their disease in medicine) or to a cog in an inhuman machine (a criticism of both communism and capitalism). People want to be valued, and they often do not feel so in the modern world. Another factor is that science, which often claims to have the objective truth at a given moment, soon disproves this very truth. At the end of the last century Newtonian physics appeared to explain all reality from the motion of small particles to the motion of the planets. Time and space were absolute. Twentieth century science has undermined this model. The theories of relativity, quantum mechanics and chaos have made time and space far less certain and absolute, and nature's patterns less linear and predictable. Medicine still works largely by nineteenth century science. Perhaps because twentieth century developments in science are so complicated applying these theories as a doctor is overwhelmingly daunting. However, chaos theory may have specific applications to psychiatry (Reid, 1998).

Many people have rejected a modernism that has claimed to discover absolute truth through observation, measurement and reason. They do 
not accept that reality can be reduced to what is measured and seek a view of the world which incorporates the whole and does not reduce it to component parts. Post-modernism is a difficult theory to define. It has origins in linguistics and is concerned with the process of knowing and how our minds are part of that process. It does not hold to objective reality but the relative reality for that individual participating in the process. Beliefs do not arise in isolation and scientific discourse is rooted in the social community of scientists (Mathers \& Rowland, 1997). Thus, the main values of post-modern theory are those of uncertainty, difference in views and experience of reality and multifaceted descriptions of truth. Leggett (1997) predicts that as a consequence of this movement, patients may turn away from statistically determined treatments as having no relevance to them as an individual: What is right for the majority may not be right for me'.

\section{Evidence-based medicine}

The movement to evidence-based medicine is clearly modernist. The underlying philosophy is that medical interventions should be rational, be measurable and observed to have benefited the recipient of the intervention. This benefit will usually have used a measure of a certain variable of the individual rather than a measure of the whole person. In psychiatry the necessity of measurement has led to the proliferation of rating scales - scales for mood, psychotic symptoms, even of strength of spiritual belief and loneliness. One of the reasons for the success of cognitive therapy has been in demonstrating its effectiveness through the use of rating scales. The 'gold standard' of evidence-based medicine is the randomised-controlled trial, and the Cochrane Library provides easily accessible information on the evidence from these trials.

Evidence-based medicine is very good for dealing with inconsistencies between health care professionals. It stops 'quackery' - practitioners inflicting their maverick theories on the unsuspecting patient. However, problems arise when the patient wants to be treated as an individual and questions whether he or she fits into a statistical norm - he or she may feel that they are not an individual being cared for, but a syndrome or disease being treated. Evidence-based medicine is not music to a post-modern ear.

\section{User involvement}

User involvement is a movement with its roots in a consumerist model of market economics together with advocacy of civil rights for the sufferers of mental illness. It is concerned with what people want - their 'needs' are often seen as being determined by paternalistic professionals. In this sense the movement has post-modern leanings, an emphasis is placed on the individual's perception of their need and not on being part of a population with common problems and common solutions.

The rise of counselling in general practice is an example of the tensions between evidence-based medicine and user involvement. This service has often been met with scepticism by psychiatrists citing claims of a lack of evidence for its effectiveness. But general practitioners claim that they are providing what their patients' want. The position of some psychotherapies has also been questioned because of a lack of empirical evidence of their effectiveness. This is partly because, as more interactive disciplines, they are much harder to research. Counselling and psychotherapy are often what patients want because they feel they are treated as individuals telling their own, unique stories. The narrative of peoples' lives has always been given importance - the story of the person, their family, their community, for example in psychiatric history-taking (Beveridge, 1998; Greenhalgh, 1999). However, patients often feel alienated by less personal interventions and rifts develop between clinicians and patients.

\section{Discussion}

It is likely that the conflict between modernism and post-modernism will affect many areas of society. Times of change in world views often lead to turmoil and chaos. There is a chance that post-modernism is a passing phenomenon, and some commentators view it as destructive, believing medicine should stick with a tried and trusted modernist paradigm (Charlton, 1993). But if post-modernism is here to stay, medicine will need to live with the tension. Psychiatry has always had post-modern leanings. The psychiatric establishment has often seemed at pains to extinguish the work of R. D. Laing, saying his ideas were flawed and did not work. The public at large, however, refuse to forget him, perhaps because he listened to patients and did not reduce them to their psychopathological components. There is a pressure on the profession to make our model more modernist through evidence-based medicine and outcome measures. The leaders of our profession are good researchers, but not necessarily good clinicians (though undoubtedly some are excellent at both). They have a lot to lose by questioning the modernist paradigm which has brought so much good to the world through medicine. If we do not question it, patients will.

There may be an increase in differences between what the psychiatrist advises and what the patient wants. As well as the psychiatrist dealing with this dilemma, patients must also 
take responsibility for this situation. Doctors cannot be expected to use scant resources on interventions they have strong reasons to believe will be ineffective. The potential for difficulties is exacerbated by the new powers of coercion and detention being suggested in mental health by the government.

Medicine and psychiatry need to assert themselves as humanities which include the art of compassion and scientific endeavour as components. They are not primarily sciences, but incorporate science as part of the whole. There is a vital role for evidence-based medicine, but we must not become slaves to it (as many of its proponents have recognised). We should select and examine our junior doctors on their ability to listen to and incorporate patients' narratives into their care as well as evaluate evidence (Greenhalgh, 1999). We need to ensure that doctors are not confined by time pressures to deliver empirical interventions and leave the human side of mental health care to colleagues in other professions (who are then accused of not being evidence-based in their work). Finally, we need to prepare for the tension between the modern and post-modern world views with the strengths and weaknesses of both. This tension will probably be with us for decades.

\section{Acknowledgement}

I wish to thank Tom Burns for his helpful comments on this article.

\section{References}

BEVERIDGE, A. (1998) The detective, the psychiatrist and post-modernism. Psychiatric Bulletin, 22. 573-574.

ChartTon, B. (1993) Medicine and post-modernity. Joumal of the Royal Society of Medicine, 86, 497-499.

GREENHALGH. T. (1999) Narrative-based medicine in an evidence-based world. Brttish Medical Joumal, 318 , 323-325.

LEGGETT, J. (1997) Medical scientism: good practice or fatal error. Journal of the Royal Society of Medicine, 80. 97-101.

MATHERS, N. \& ROWLAND, S. (1997) General practice - a post-modern speciality. British Journal of General Practice, 47, 177-179.

REID, S. (1998) Butterflies, fractals and psychiatry. Psychiatric Bulletin, 22, 568-570.

Richard Laugharne, Consultant Psychiatrist, Department of General Psychiatry. St George's Hospital Medical School, University of London. Jenner Wing, Cranmer Terrace, London SW17 ORE

\section{Recent Topics from Advances in Psychiatric Treatment: Volume 2 Affective and Non-Psychotic Disorders} Edited by Alan Lee

This book discusses the evidence-based assessment of deliberate self-harm, and covers the special problems of general psychiatric practice when alcohol misuse and severe personality disorder complicate the picture. Chapters relating to

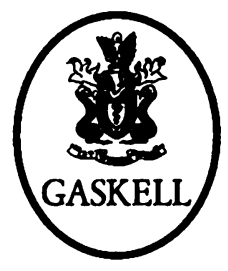
depressive disorders begin by focusing on opportunities for psycho-social intervention and liaison with primary care. There are comparisons of 'old' and 'new' antidepressants, and reviews of strategies for preventing relapse and recurrence, and managing resistant depression. The special problems of emergency treatment and depression in older patients are identified.

There are expert overviews of brief dynamic psychotherapy, cognitive approaches to treatment, lithium therapy and modern ECT practice. Many chapters emphasise the importance of the rational integration of biological and psychological treatments. There is helpful advice on the specific problems in managing obsessive-compulsive disorder and eating disorders, in dealing with somatisation, and in providing support and treatment for the victims of severe trauma.

\section{October 1999, f15.00, 160pp, Paperback, ISBN 190124217 X}

Royal College of Psychiatrists, Book Sales, 17 Belgrave Square, London, SW1X 8PG Tel: 01712352351 ext 146, Fax: 0171245 1231, 9.30am - 2.00pm. 